\title{
Autogenic translation and concave bank deposition in meandering rivers
}

\author{
Zoltán Sylvester ${ }^{*}$, Paul R. Durkin ${ }^{2}$, Stephen M. Hubbard ${ }^{3}$, David Mohrig ${ }^{4}$ \\ 1 Bureau of Economic Geology, Jackson School of Geosciences, The University of Texas at \\ Austin \\ 2 Department of Geological Sciences, University of Manitoba \\ 3 Department of Geoscience, University of Calgary \\ 4 Department of Geological Sciences, Jackson School of Geosciences, The University of Texas \\ at Austin
}

* corresponding author, zoltan.sylvester@beg.utexas.edu

This is a non-peer-reviewed preprint submitted to Eartharxiv.

\begin{abstract}
Although it has long been recognized that deposition along meandering rivers is not restricted to convex banks, the consensus is that external forcing, that is, confinement by an erosion-resistant barrier, is necessary for significant concave-bank deposition to occur. Using a kinematic model of channel meandering and time-lapse satellite imagery from the Mamoré River in Bolivia, we show that downstream translation and the associated concave-bank deposition are essential, autogenic parts of the meandering process, and they are expected to be present whenever perturbations such as bend cutoffs and channel reoccupations create shorter bends with high curvatures. The implication is that zones of concave-bank deposition with lower elevations, relatively fine-grained deposits, stagnant water bodies, and riparian vegetation different from what is characteristic of point bars are more common than previously considered.
\end{abstract}

\section{Introduction}

Meandering rivers are ubiquitous on the surface of the Earth and have shaped the surface of Mars in the past. Some meandering rivers migrate several tens of meters per year (Constantine et al., 2014); and predicting channel location and the related spatial distribution of water, sediment, and riparian vegetation is important for a series of problems like agricultural land management, bridge design, loss of real estate and infrastructure, and distribution of pore space in the resulting sediments and sedimentary rocks. While both modeling and observations suggest that the kinematics of meandering is more complicated than simple bend expansion, the classic model of largely coarse-grained deposition on convex banks / point bars still dominates our basic understanding of these systems. Although in recent decades it has been increasingly recognized that deposition along concave banks and development of counter point bars occur along many meandering rivers (Page and Nanson, 1982; Makaske and Weerts, 2005; Smith et al., 2009; Ielpi and Ghinassi, 2014; Durkin et al., 2015, 2017; Ghinassi et al., 2016), these features are interpreted to result only under special circumstances such as downstream channel migration caused by decreased bank erodibility.

Counter point bars form adjacent to and downstream of typical point bars, where lateral accretion takes place along a concave bank of channel bends, resulting in concave scroll patterns (Smith et al., 2009; Fig. 1). This simple and broad geometric definition is identical with 'concave-bank deposits' (Willis and Tang, 2010); see Smith et al. (2009) for a discussion of other related, but more specific terms like 'eddy accretion deposits' and 'concave-bank bench deposits'. Few studies of modern and ancient meander-belt deposits have identified counter-point bar deposits, likely due to the qualitative and limited recognition criteria. Although the number of well-documented field examples is limited, the existing data suggest that counter point bars are 

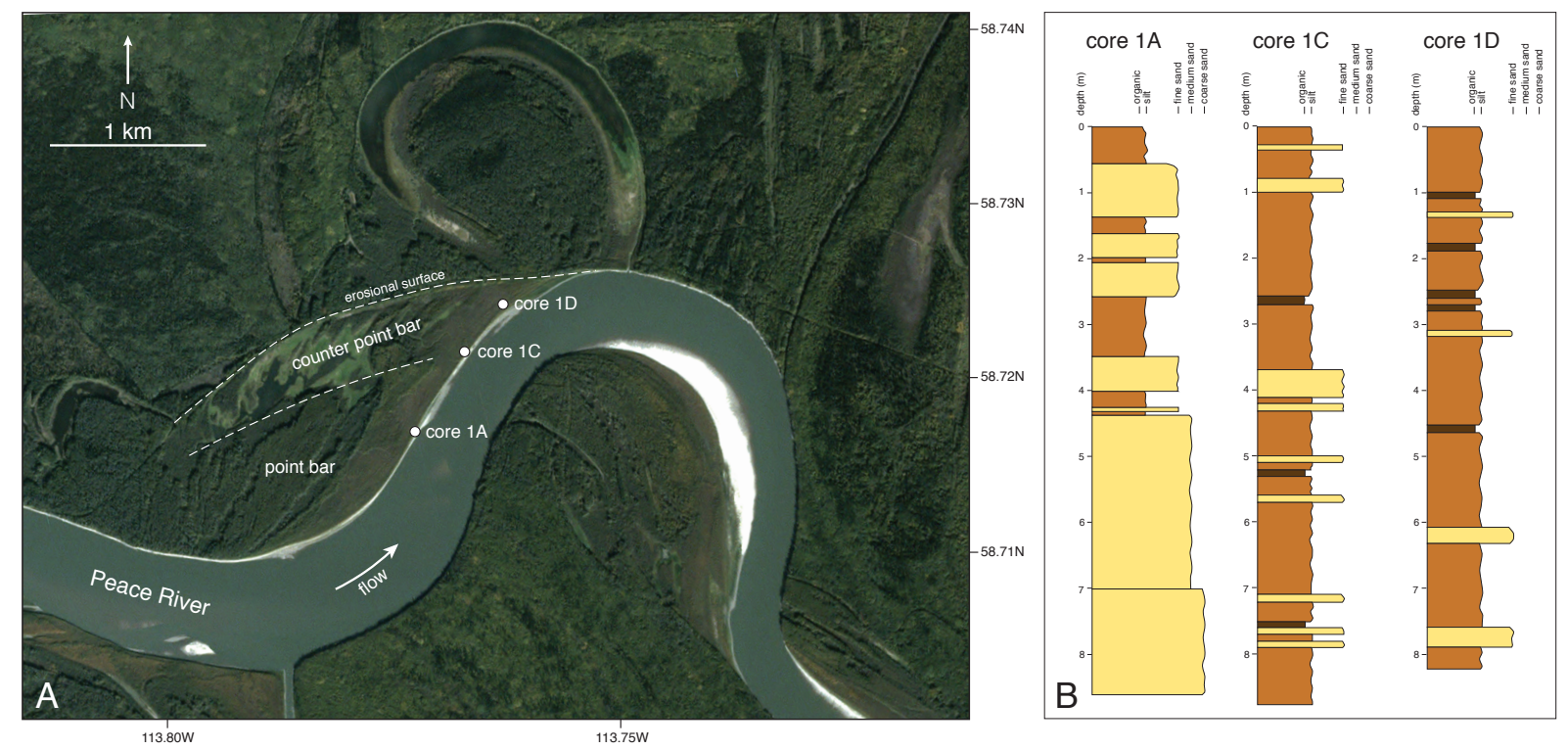

Figure 1. A counter point bar from the Peace River, Alberta, Canada. (A) Satellite image of a bend that displays concave bank deposition. (B) Lithologic logs of cores taken at locations shown in (A). Redrawn from Smith et al. (2009). Image in (A) courtesy of Planet Labs Inc.

overall finer grained than adjacent point bars and they can be dominated by silt- and mud-grade sediment (Hickin, 1979; Page and Nanson, 1982; Makaske and Weerts, 2005; Smith et al., 2009; Hubbard et al., 2011; Durkin et al., 2015, 2017, 2018). As a result, the heterogeneity of meandering river deposits is probably significantly larger, and the distributions of permeability and porosity are more complex than simple point-bar-based models imply (Smith et al., 2009; Durkin et al., 2017).

The formation of counter point bars has been linked to downstream translation of meander bends. Bend translation refers to a lateral shift in bend location that is not associated with a significant increase in amplitude and arc length. This is in contrast with bend expansion that, in its purest form, involves stationary inflection points and a growing bend amplitude and arc length. Downstream translation has been attributed to reduced erodibility along the outer bank (Smith et al., 2009; Willis and Tang, 2010; Ghinassi et al., 2018). Indeed, some of the most striking examples of downstream translation and concave-bank deposition occur along rivers that are clearly confined by escarpments resistant to erosion (e.g., Page and Nanson, 1982; Hickin, 1986). Although it has been recognized that counter point bars are also present in wider, overall unconfined meander belts, they are still interpreted as the result of translation due to the presence of low-erodibility material along the outer bank (Smith et al., 2009; Ghinassi et al., 2016). However, the existence of this kind of allogenic forcing is not always obvious; for example, there is no clear evidence in aerial imagery that the translation of counter point bar number 1 of Smith et al. (2009) would be caused by low erodibility (Fig. 1). As suggested by Smith et al. (2009, their Fig. 1), the question arises whether significant downstream translation, and therefore concave-bank deposition, can take place without substrate variability, that is, in an autogenic fashion.

A second question is whether it is possible to improve the existing approaches to identify counter point bars. Up until now, the definition of and recognition criteria for such river segments and their deposits have been qualitative. Here we present a simple parameter that is relatively easy to estimate and can be used to define and identify counter point bars in an objective and reproducible way.

A third question focuses on the possibility of going beyond simply subdividing meandering river deposits into point bars and counter point bars. That is, channel segments with deposition on the concave bank have variable geometries and - probably - variable deposits. Their two main characteristics, bank concavity (or curvature) and rate of accretion (or migration rate), are likely to vary across a range; yet this variability and its potential impact on counter-point-bar geometry and stratigraphy have not been explored before. In addition, the relationship between curvature and migration rate has been the subject of numerous studies 
(e.g., Hickin and Nanson, 1975; Furbish, 1988; Hudson and Kesel, 2000; Güneralp and Rhoads, 2009), but it is unclear how curvature-driven meander kinematics is related to bend translation, expansion, and the presence or absence of counter point bars.

In this study, we aim to address these questions by exploring the relationships between the kinematics of meandering, downstream translation, and counter point bars. We use a simple model of meandering to illustrate and quantify these relationships; and we put forward a new parameter for differentiating counter point bars from point bars and to estimate the likelihood of counter point bar occurrence: a combined measure of the sign and magnitude of both curvature and migration rate. We apply the insights gained from modeling to Landsat time-lapse imagery of the Mamoré River in Bolivia.

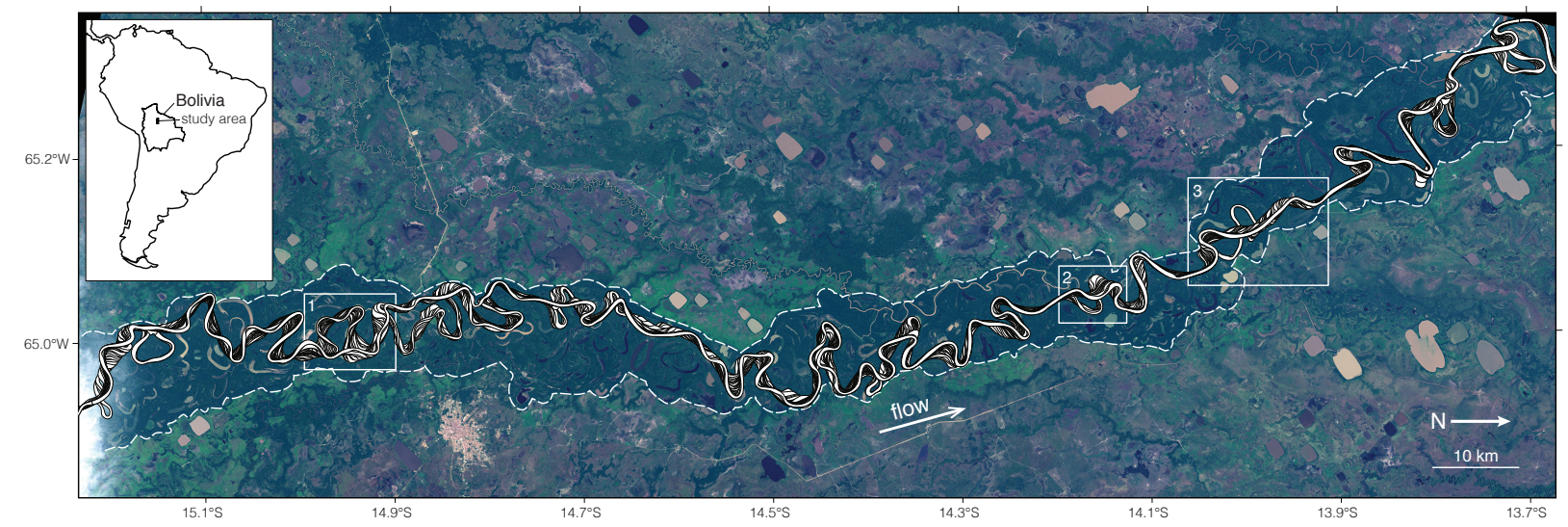

Figure 2. Landsat satellite image showing a segment of the Mamoré River and the interpreted channel locations between 1986 and 2018.

\section{Methods}

\subsection{Mapping River Banks in Satellite Imagery}

We have selected a $375 \mathrm{~km}$ long segment of the Mamoré River in Bolivia to investigate channel migration through time and track the development of counter point bars. The segment is covered by one Landsat scene, with imagery of reasonable quality available starting with 1986 (Fig. 2). The Mamoré River drains an area of $600,000 \mathrm{~km}^{2}$ at an average discharge of 2,980 $\mathrm{m}^{3} / \mathrm{s}$ (Thames et al., 1993; Aalto et al., 2003). Over the study interval, the average channel width is $376 \mathrm{~m}$, with a bankfull depth of $12 \mathrm{~m}$ (Thames et al., 1993). Grain size (d50) of suspended sediment is 9.0 microns and bed material is 400 microns (Guyot et al., 1999). As the Mamoré drains parts of the Andes, it carries a large sediment load and its channel migration rates are among the highest measured on Earth, on the order of tens of meters per year (Constantine et al., 2014). In addition to the overall high rates of channel migration, significant downstream translation can be observed in several locations. Although the channel belt is clearly affected by low erodibility along its boundaries, there are numerous meander bends that seem to be freely meandering. One Landsat scene per year was downloaded from the USGS Earth Explorer site (https://earthexplorer.usgs.gov/). Most of the selected scenes were collected in July or August, as these scenes tend to have reduced cloud cover. Due to lack of data of reasonable quality, no scenes were used from 2002 and 2012.

To increase the speed of interpretation and improve reproducibility, we have detected channel banks using a quasi-automated workflow, based on the Python package RivaMap (Isikdogan et al., 2015, 2017). The input to the RivaMap algorithm is the Modified Normalized Difference Water Index (MNDWI; Xu, 2006). In the MNDWI image, rivers are identified using the multiscale singularity index, an index that enhances curvilinear features. Once the curvilinear bodies of water are highlighted, river centerlines are generated through non-maxima suppression along the dominant orientation. For additional details on the RivaMap centerline generation see Isikdogan et al. (2017).

Although the RivaMap package can be used to generate not only centerlines but river width data as well, 
it does not create a single continuous centerline and left and right banks for the channel of interest.

Therefore, we have written a new workflow to (1) extract the centerline of the Mamoré as an

upstream-to-downstream ordered array of pixel locations; and (2) extract the left and right banks as ordered arrays of the same length and orientation as the centerline. This workflow is not entirely automated, as both the centerline and the thresholded water index need to be manually edited using image editing software, but it is less time consuming and more reproducible than an entirely manual interpretation. To obtain relatively smooth centerlines from the pixel-based data points, we have applied a Savitzky-Golay filter (Savitzky and Golay, 1964), with a footprint of 21 points; then, to reduce the noise in the curvature data, we have resampled and smoothed the centerlines and the banks again, by using a B-spline representation. The distance between consecutive points along the centerline was set to $25 \mathrm{~m}$. As a last step in processing the banks, we have resampled them so that for every point on the centerline there is a corresponding point on each bank, located along a direction perpendicular to the centerline. The end result is that all three curves have the same number of points, they all vary relatively smoothly, and all have curvature vectors with limited noise. By using these points, the channel planform can be divided into small polygons of equal length along the centerline, and these polygons can then be used to visualize parameters characteristic of that location along the channel.

Once the channels are extracted from each Landsat scene, migration rates can be estimated using two consecutive channel centerlines. We do this by looking for the nearest point on the second centerline for each point on the first centerline. Ideally the migration rate should be computed along a line perpendicular to the channel centerline; and this is not what a nearest-point approach does. However, if the distances between the centerlines and between the points along the centerlines are not too large, the nearest-point approach gives a good approximation of the migration distances in the perpendicular direction. To speed up the computation of migration rate, we use a dynamic time warping algorithm that is often used to correlate two time series and relies on dynamic programming (e.g., Lisiecki and Lisiecki, 2002).

To check the results of the channel tracking, true color images were created from the Landsat bands and compared against the detected channel banks. However, only limited detail is visible in the Landsat imagery as the pixel size is $30 \mathrm{~m}$. To compare maps of channel migration against the current distribution of water bodies, scroll bars, and other surface features, we have created true color images with $3 \mathrm{~m}$ resolution from Planet Ortho Visual 4-band scenes, courtesy of the company Planet Labs, Inc.

The Python scripts used for processing the satellite images and the channel centerlines and banks, in the form of Jupyter notebooks, are available from the first author.

\subsection{Kinematic Model}

Counter point bars are defined as locations of concave bank accretion (Smith et al., 2009). The concave / convex nature of the channel at any given location can be quantified using a curvature estimate; and the speed of bank accretion for a channel with invariant width is identical to migration rate. Thus, curvature and migration rate are the two parameters that need to be measured if we wanted to quantify the location and evolution of counter point bars. In terms of curvature and migration rate, the concept of concave bank deposition is equivalent to the following formulation: counter point bars form where the channel migrates in the opposite direction of what is expected from the orientation of the local curvature vector. In other words, deposition occurs at sites where erosion is predicted.

To develop a better understanding of how curvature and migration rate are related, and why they have opposite signs in places, we rely on the simple kinematic model of Howard and Knutson (1984). In this model, migration rate is a function of the weighted sum of the upstream curvatures; although no velocities are computed, this formulation is equivalent to the dynamic model of Ikeda et al. (1981). In the approach adopted by Howard and Knutson (1984), curvature is used in the form of a 'nominal migration rate', which is estimated using an empirical relationship between curvature and migration rate. The idea is that this empirical relationship would be based on field measurements, like those of Hickin and Nanson (1975). We have argued elsewhere (Sylvester et al., 2019) that the relationship between curvature and migration rate is not as complicated as the data of Hickin and Nanson (1975) suggest. Therefore, we simplify the Howard and Knutson (1984) approach, and define the nominal migration rate $M_{0}$ as the product of the dimensionless 

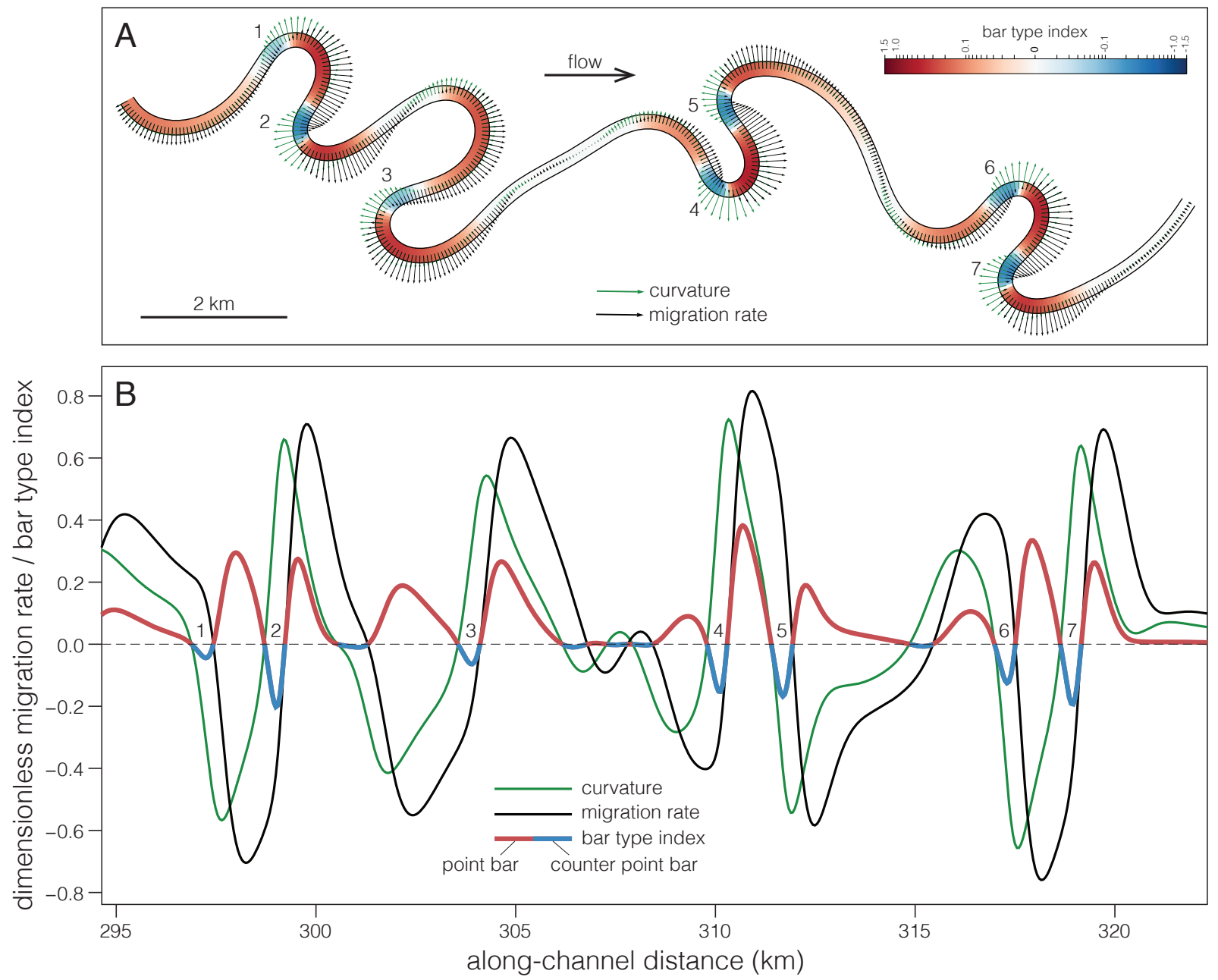

Figure 3. Illustration of the bar type index with a kinematic model. (A) Nominal migration (or curvature), predicted migration, and bar type index along a model channel segment. Well-defined counter-point bar locations numbered from 1 to 7. (B) Along-channel variation of dimensionless curvature, migration rate, and bar type index.

curvature $\left(W / R\right.$, where $W$ is channel width and $R$ is radius of curvature) and the migration rate constant $k_{l}$ :

$$
M_{0}=\frac{k_{l} W}{R}
$$

The predicted migration rate $M_{1}$ is the weighted sum of upstream curvatures:

$$
M_{1}(s)=\Omega M_{0}(s)+\left(\Gamma \int_{0}^{\infty} M_{0}(s-\xi) G(\xi) d \xi\right)\left(\int_{0}^{\infty} G(\xi) d \xi\right)^{-1}
$$

where $\Omega$ and $\Gamma$ are weighting parameters with values of -1 and 2.5 , and $G(\xi)$ is an exponential weighting ${ }_{136}$ function:

$$
G(\xi)=e^{-\alpha \xi},
$$

where $\alpha$ is a function of friction factor $C_{f}$ and spatially averaged water depth $D$ :

$$
\alpha=2 k C_{f} / D .
$$

In each time step, points along the centerline are moved in a direction perpendicular to the centerline, ${ }_{139}$ using migration rates computed with equation (2). The migration rate constant $k_{l}$ is fixed along the 
centerline and throughout the simulation; this also means that no spatial variability in erodibility is the end of the centerline are fixed.

Using this model, it is possible to investigate how curvature and migration rate change through time along a channel and what are the potential processes that result in downstream translation and counter point bar formation.

\section{Results}

\subsection{The Bar Type Index}

It is useful to combine curvature and migration rate into a single parameter that captures (1) their magnitudes and (2) whether they are of the same or opposite sign. To capture the second parameter, we are relying on signed versions of both curvature and migration rate (Fig. 3). Migration rate is considered positive when a channel segment moves to the right of its current location, looking downstream. The simplest parameter that fits the description above is the product of the dimensionless curvature $W / R$ and normalized migration rate $M / k_{l}$, where $k_{l}$ is the migration rate constant:

$$
B T I=\frac{W}{R} \frac{M}{k_{l}} .
$$

We call this quantity the 'bar type index', a dimensionless parameter that can be used to identify the location and likelihood of counter-point bar development. Counter point bars are likely to develop where the bar type index is negative and has a relatively large absolute value. As both dimensionless curvature and normalized migration rate tend to have values between -1 and 1 , the magnitude of bar type index is commonly bounded between these two values. A modeled channel segment can be used to illustrate the typical spatial distribution of curvature, migration rate, and bar type index (Fig. 3). Curvature and migration rate have opposite signs in several locations, as a result of the spatial lag between the two curves: the migration rate curve is shifted downstream relative to curvature. Occurrence of a lag is an important aspect of meandering, predicted by theory (e.g., Sun et al., 1996; Seminara, 2006) and confirmed by measurements in time-lapse satellite imagery (Sylvester et al., 2019). In the kinematic model used here, the lag is due to the fact that migration rate is not only a function of the local curvature (in this case there would be no lag), but it is the integral of upstream curvatures (eq. 2; Furbish, 1991).

Because this phase lag tends to be significantly smaller than the half wavelength of the channel bends, curvature and migration have opposite signs (and the bar type index negative values) along segments that are shorter than segments with the same sign. In other words, the kinematic model results in a larger fraction of point bars than counter point bars. The length of the segments with negative BTI is the same as the phase lag; as the phase lag tends to be about the same along the channel, the length of the counter point bars tends to stay the same in the model. However, the magnitude of the BTI is highly variable, ranging from only slightly negative values to well-defined peaks of about -0.2 (Fig. 3). Large absolute values of the BTI are associated with bends of high overall curvature; as migration rate is a quasi-linear function of curvature, these bends also have high migration rates.

\subsection{Mamoré River examples}

Within the larger area of interest, we have selected three areas for a more detailed analysis of channel evolution (Figs. 2, 4). All three areas cover channel segments showing zones of significant downstream bend translation that are unlikely to be guided by erosion-resistant barriers (i.e. channel-belt boundaries; Fig. 2). Instead, in all three cases the translation seems to be related to significant recent changes in the channel configuration, e.g., bend cut-off. 

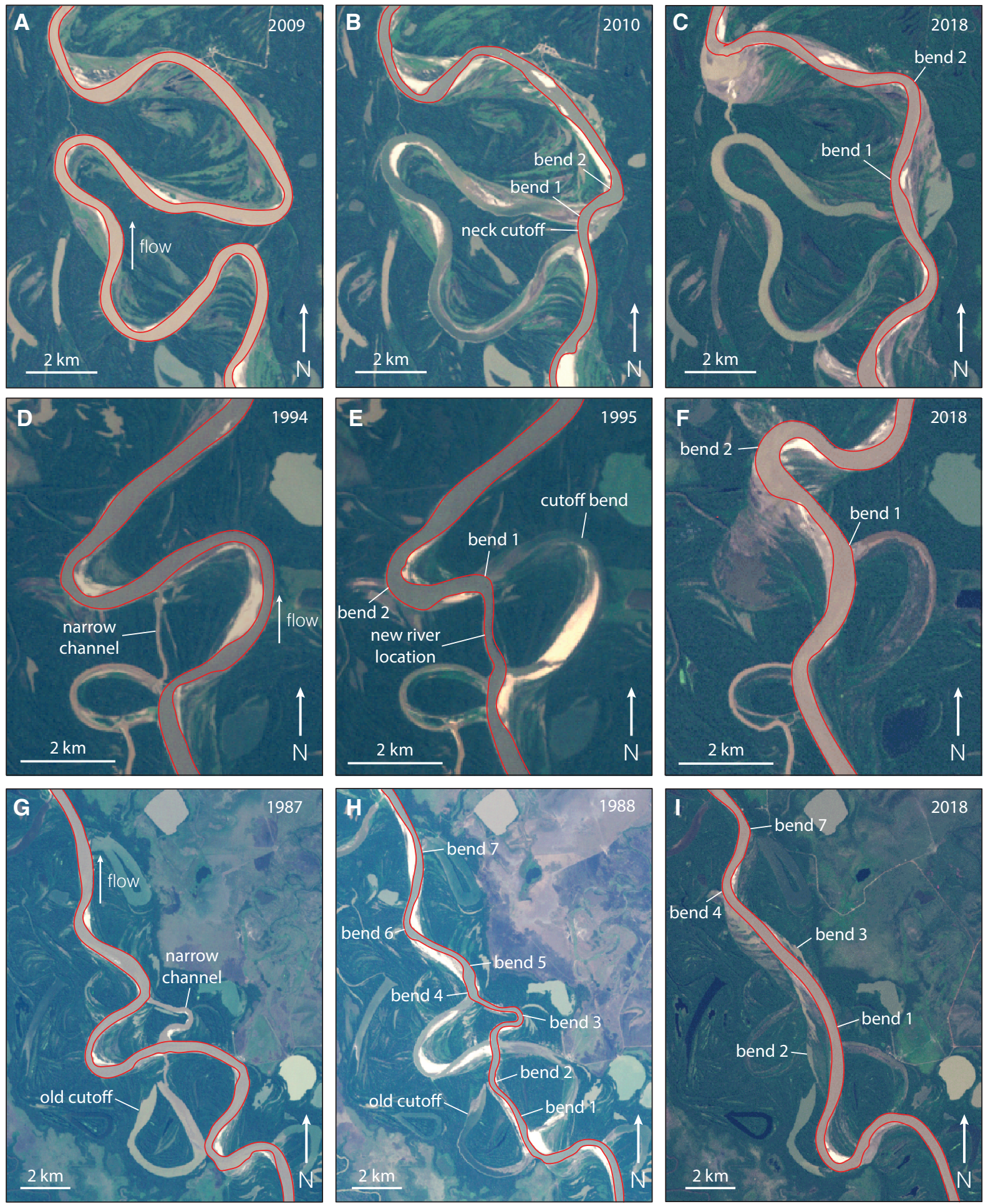

Figure 4. Time-lapse Landsat images of the three Mamore River segments analyzed in detail. A, B, C images from 2009, 2010, and 2018 showing the evolution of a neck cutoff (area 1 in Fig. 2). D, E, F - images from 1994, 1995, and 2018, of a cutoff associated with channel reoccupation (area 2 in Fig. 2). G, H, Iimages from 1987, 1988, and 2018, showing the evolution of a channel reorganization event associated with the reoccupation of an oxbow lake and a narrow channel (area 3 in Fig. 2). 
In the first case, a large meander bend underwent a neck cutoff sometime between July 2009 and July 2010 (Fig. 5). As a result, two short and relatively sharp bends formed (bend 1 and 2 in Fig. 5C). After 2010, bend 2 rapidly migrated downstream and left behind a $3 \mathrm{~km}$ long zone with concave bank deposits. The bar type index is negative as well in this zone, with the largest absolute values recorded soon after the cutoff event, in the oldest part of the counter point bar (Fig. 5C). The satellite images and the MNDWI map suggest that this zone tends to have low elevations, as indicated by the presence of a number of lakes. The largest lake has formed close to the cutoff location and corresponds to the lowest BTI values (Fig. 5D). Although the apex of bend 1 has also moved downstream, its concave bank was not depositional; after the cutoff event, bend 1 has undergone an increase in wavelength and decrease in curvature. Further downstream, at bend 5, a second zone of concave bank deposition has also developed during the same time period. It is possible that this translation was also driven by the neck cutoff.

The second example also involves a bend cutoff; however, in this case the river took advantage of a pre-existing narrow channel to cut off a bend that was far from a stage where a neck cutoff would normally be expected to occur (Figs. 4, 6). This narrow channel linked an old oxbow lake with the main channel in 1994 and took over most of the discharge by August 1995. As a result, a sharp bend (bend 1) formed on the downstream side of the cutoff bend. This change caused the downstream bend (bend 2) to switch from expansion and point bar deposition to downstream translation and significant concave bank deposition (Fig. 6C). Like in case 1, the bar type index is negative in this zone of translation and has its highest absolute value for deposits formed immediately after the cutoff event. Another similarity with case 1 is the evolution of bend 1: its wavelength increases, and its curvature decreases through time; the associated bar type index is mostly positive; and the satellite images suggest typical sand-rich point bar deposition along a majority of the bend (Fig. 6A, 6C). The translational zone of bend 2 is covered by a number of lakes, and the largest

lake is located at the oldest part of the counter point bar. In the 2018 Planet Labs true color image, the transition from positive to negative bar type indices seems to correspond to the transition from sand-rich to sand-poor deposition (Fig. 6A, 6C).

The third example has the most complicated history. Two large bends were abandoned sometime between July 1987 and August 1988 (Figs. 4, 7). The abandonment of the first bend (labeled '1987' in Fig. 7C) took place as the main river channel eroded into an old oxbow lake and reoccupied one side of the oxbow and the tie channel that linked the lake to the river. The second meander was abandoned when a narrow and sinuous channel took over most of the discharge from the main channel. This probably happened because the orientation of the narrow channel coincided with the new orientation of the reoccupied branch of the oxbow lake. As a result of these abandonments and reoccupations, a new channel segment has formed that had numerous short bends, some of them with high curvatures (e.g., bend 3; Fig. 7D). In the years following the channel reorganization, most of these bends have translated downstream and formed deposits predominantly along the concave banks (Fig. 7C). Strings of lakes seem to track the areas with strongly negative values of the bar type index (Fig. 7D). During the 30 years since the cutoffs occurred, the channel planform has simplified significantly as several of the short bends disappeared; the original ten segments with distinct changes in the sign of curvature have been replaced by four much larger wavelength and overall lower-curvature bends (Fig. 7C). 

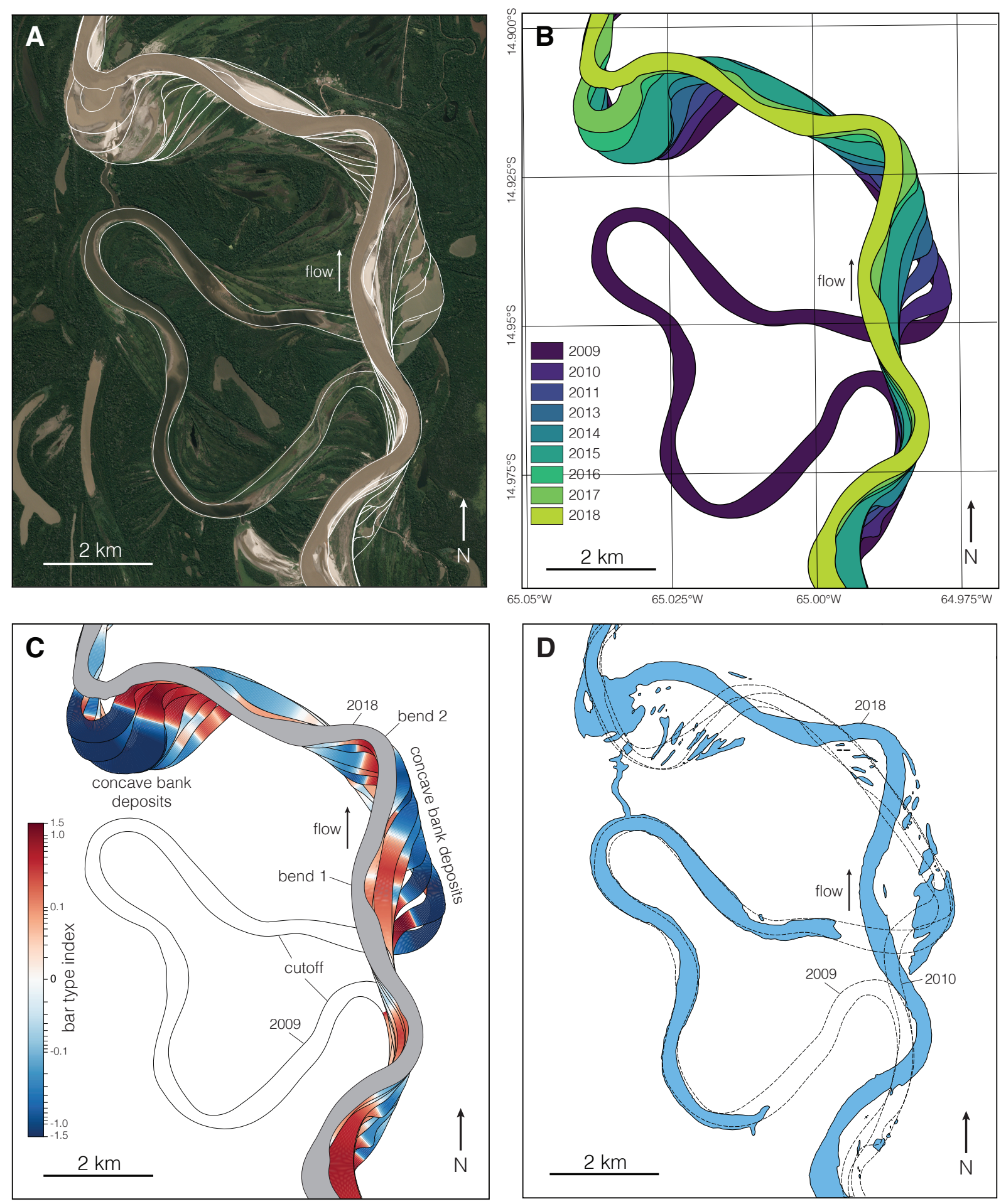

Figure 5. Satellite image and analysis of area 1 in Fig. 3, a neck cutoff. (A) Satellite image from 2018, with the 2009-2018 channel banks plotted. Satellite data courtesy of Planet Labs. (B) Channel locations from 2009 to 2018. (C) Bar type index computed for the channel locations from 2010 to 2017. (D) Extent of water bodies extracted from an MNDWI image. Only water bodies associated with the 2009-2018 channel locations are shown. 

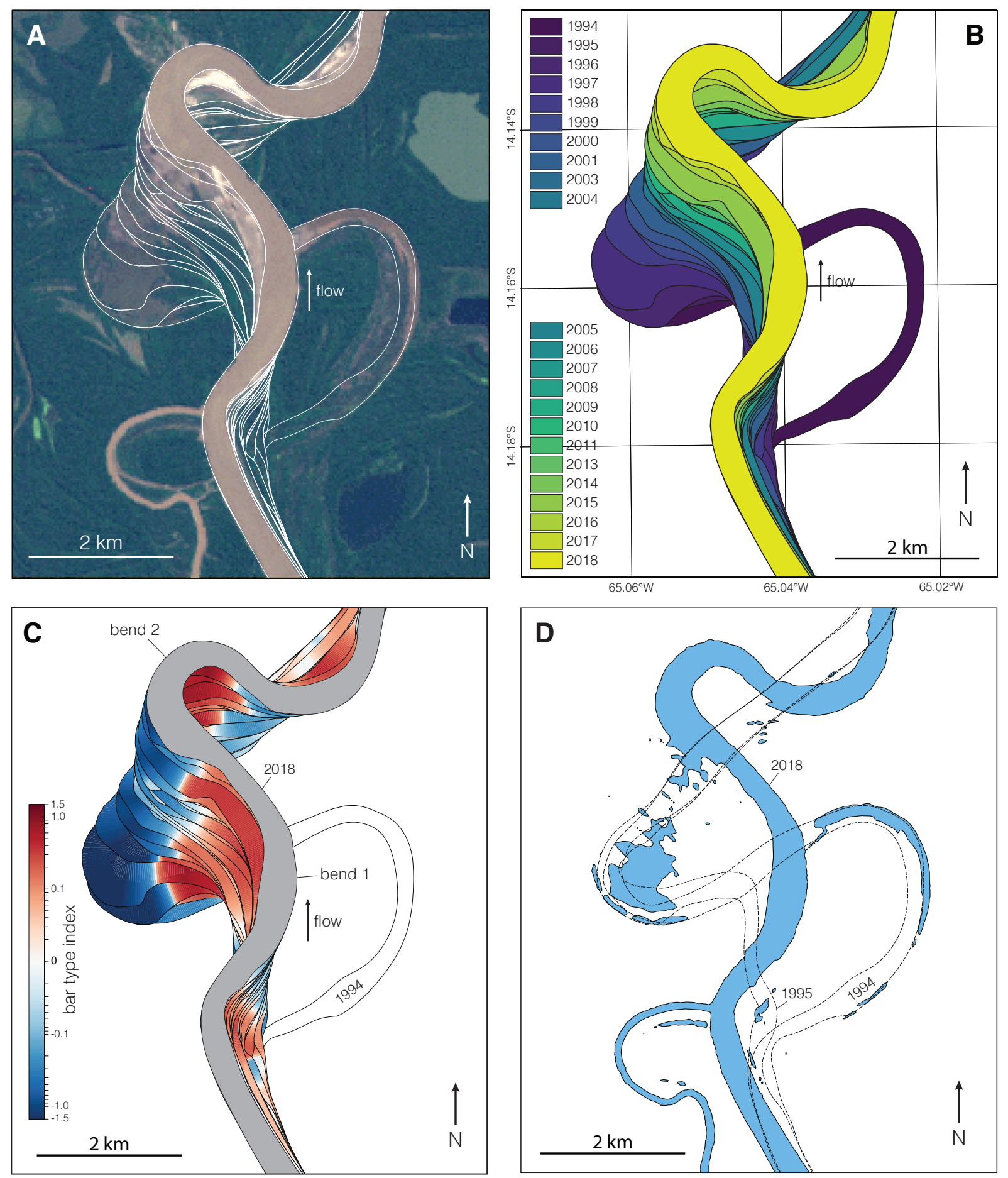

Figure 6. Satellite image and analysis of area 2 in Fig. 3. (A) Satellite image from 2018, with the 1994-2018 channel banks plotted. Satellite data courtesy of Planet Labs. (B) Channel locations from 1994 to 2018. (C) Bar type index computed for the channel locations from 1995 to 2017. (D) Extent of water bodies extracted from an MNDWI image. Only water bodies associated with the 1994-2018 channel locations are shown. 

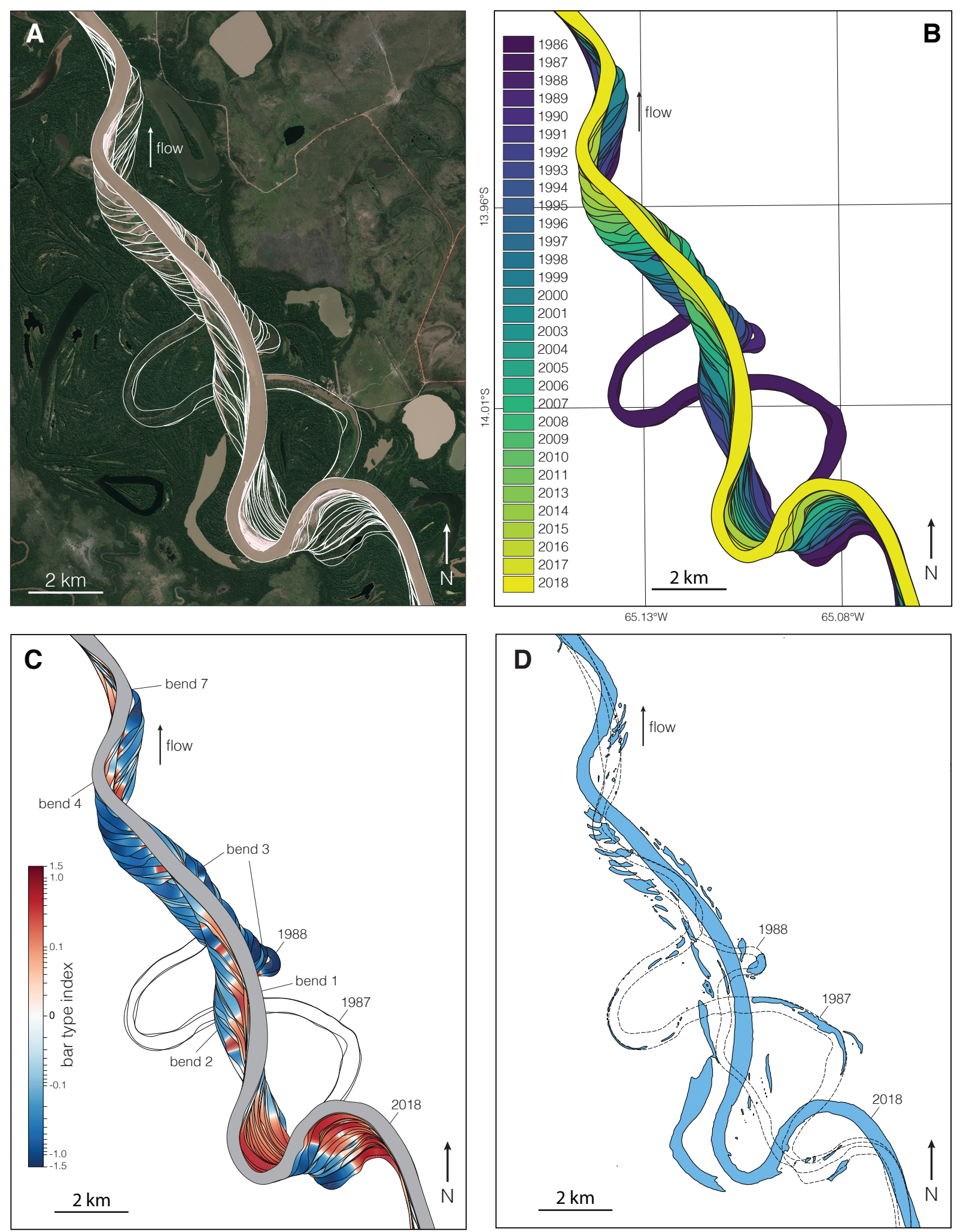

Figure 7. Satellite image and analysis of area 3 in Fig. 3. (A) Satellite image from 2018, with the 1986-2018 channel banks plotted. Satellite data courtesy of Planet Labs. (B) Channel locations from 1986 to 2018. (C) Bar type index computed for the channel locations from 1987 to 2017. (D) Extent of water bodies extracted from an MNDWI image. Only water bodies associated with the 1986-2018 channel locations are shown. 


\subsection{Counter Point Bars in the Kinematic Model}

The simple kinematic model outlined above can be used to investigate why some channel bends are dominated by expansion, whereas others undergo significant downstream translation and generate counter point bars. A first important observation is that downstream translation is present in simple models of meandering; it is the result of the phase shift between curvature and migration rate. If migration rate only was a function of local curvature, the curvature and migration rate series would be in phase and all meander bends would be purely expansional. However, if migration rate is the weighted sum of upstream curvatures, the point of maximum migration is shifted downstream from the point of maximum curvature (Fig. 3). The length of this phase lag shows limited variability for a river with similar parameters; this is true in the model (Fig. 3) and at least in some rivers (Sylvester et al., 2019). In contrast, the size of meander bends is highly variable: mature meanders are much larger than those that have formed only recently due to a cutoff or some other perturbation. Large meanders are dominated by expansion because most of the migration takes place not too far downstream from the bend apex; short bends undergo translation as the point of maximum migration falls on the downstream side of the bend, close to the inflection point (Fig. 8).

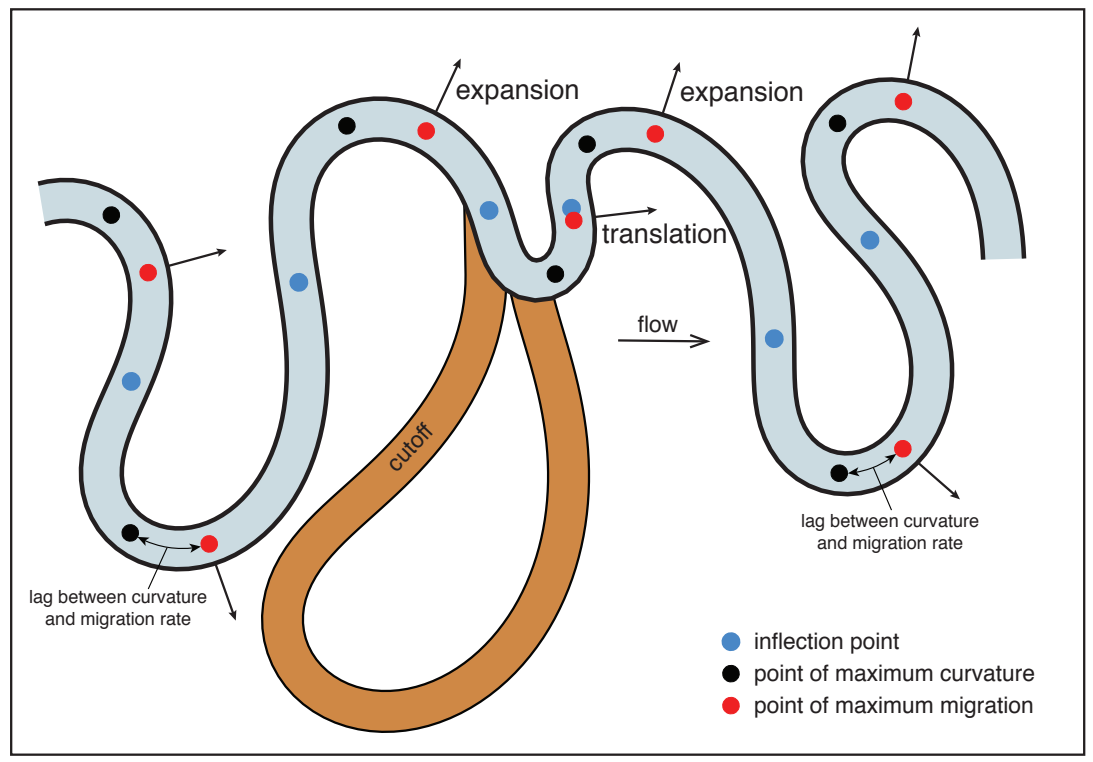

Figure 8. Modeled channel segment showing inflection points, points of maximum curvature, and points of maximum migration. Well-developed translation is associated with small bends with high curvatures.

A meander bend that has formed through neck cutoff often has a short arc length and high curvatures (Figs. 8, 9). The point of maximum migration falls on the downstream side and this results in downstream translation. Due to the increased sediment supply associated with the cutoff (Zinger et al., 2011; Schwenk and Foufoula-Georgiou, 2016) and the newly generated high curvatures, the migration rates - and therefore the translation rates - are relatively high. It is not only the bend that has formed through the cutoff process that undergoes translation; the high curvatures are transmitted downstream to the next bend as well, and, at least in some cases, even to the third bend. As a result, several zones of concave bank deposition and potential counter point bar formation develop, all of them downstream from the cutoff location (Fig. 9). Through time, the cutoff-related meanders become larger; the rate of translation decreases and expansion starts to dominate. These changes are reflected in a gradual decline of the absolute value of the bar type index for the counter point bars (Figs. 5C, 6C).

A relatively long-term simulation of river meandering allows us to visualize the preservation of both convex-bank and concave-bank deposits (Fig. 10). As counter point bars tend to be associated with finer-grained, heterogeneous deposits (Smith et al., 2009; Hubbard et al., 2011; Durkin et al., 2018), there is significantly more heterogeneity in the channel belt stratigraphy than what would be expected if only oxbow-lake fills were considered (e.g., Colombera et al., 2017). Because downstream translation is 
characteristic of relatively young meander bends, counter point bars are more common along the most recent channel location. However, deposits with negative bar type indices are preserved further away from the river as well. They are always located along erosional surfaces that result from the translation; these surfaces often directly juxtapose deposits of unrelated bars and are important when considering pore space connectivity between different bars (Fig. 10). This connectivity is reduced if mud-rich counter point bars are associated with the erosional surface.
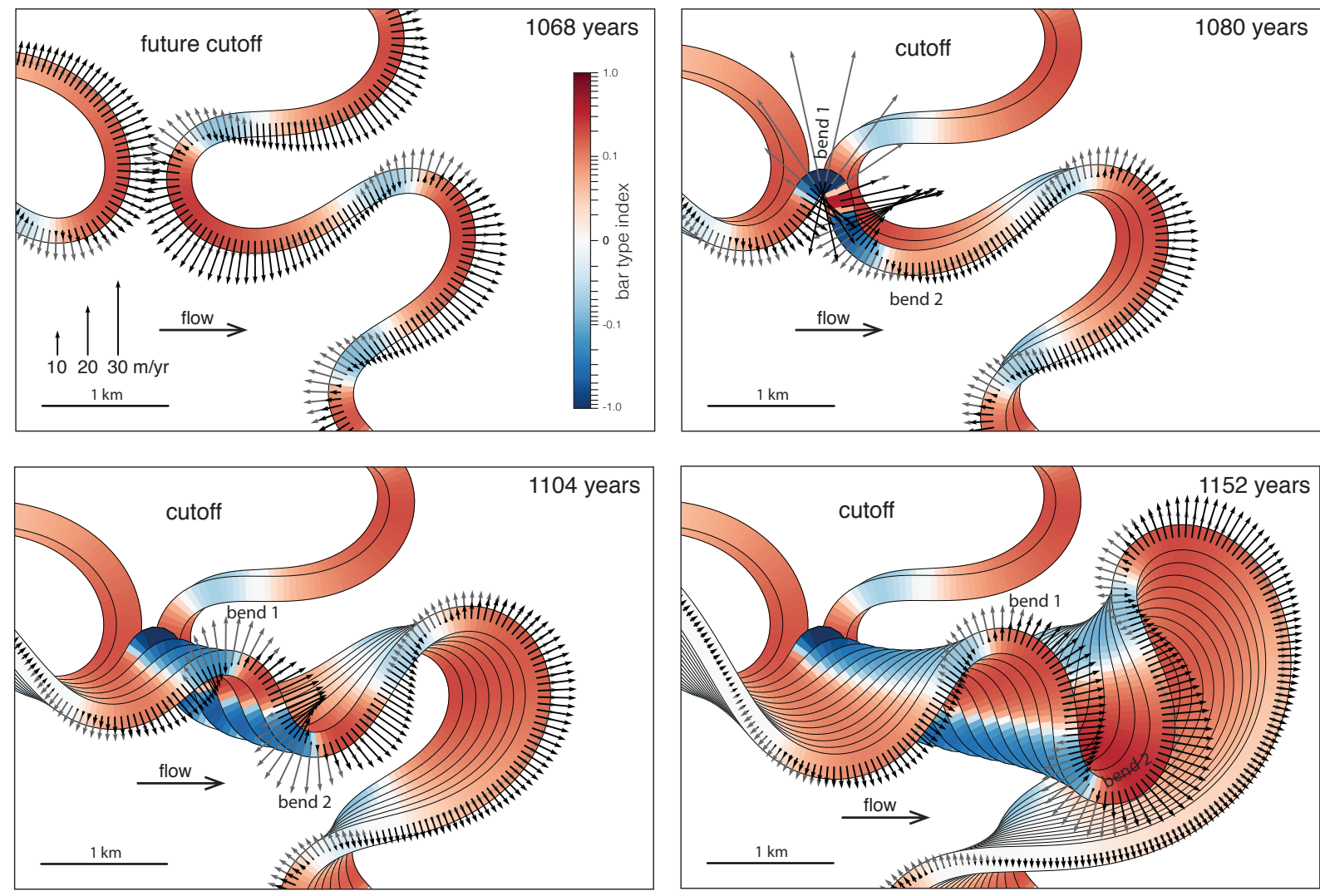

Figure 9. Four timesteps from a forward model of channel migration associated with a neck cutoff. Bar type index plotted for each channel location. Curvature (nominal migration) vectors are shown as gray arrows, migration vectors shown as black arrows. 

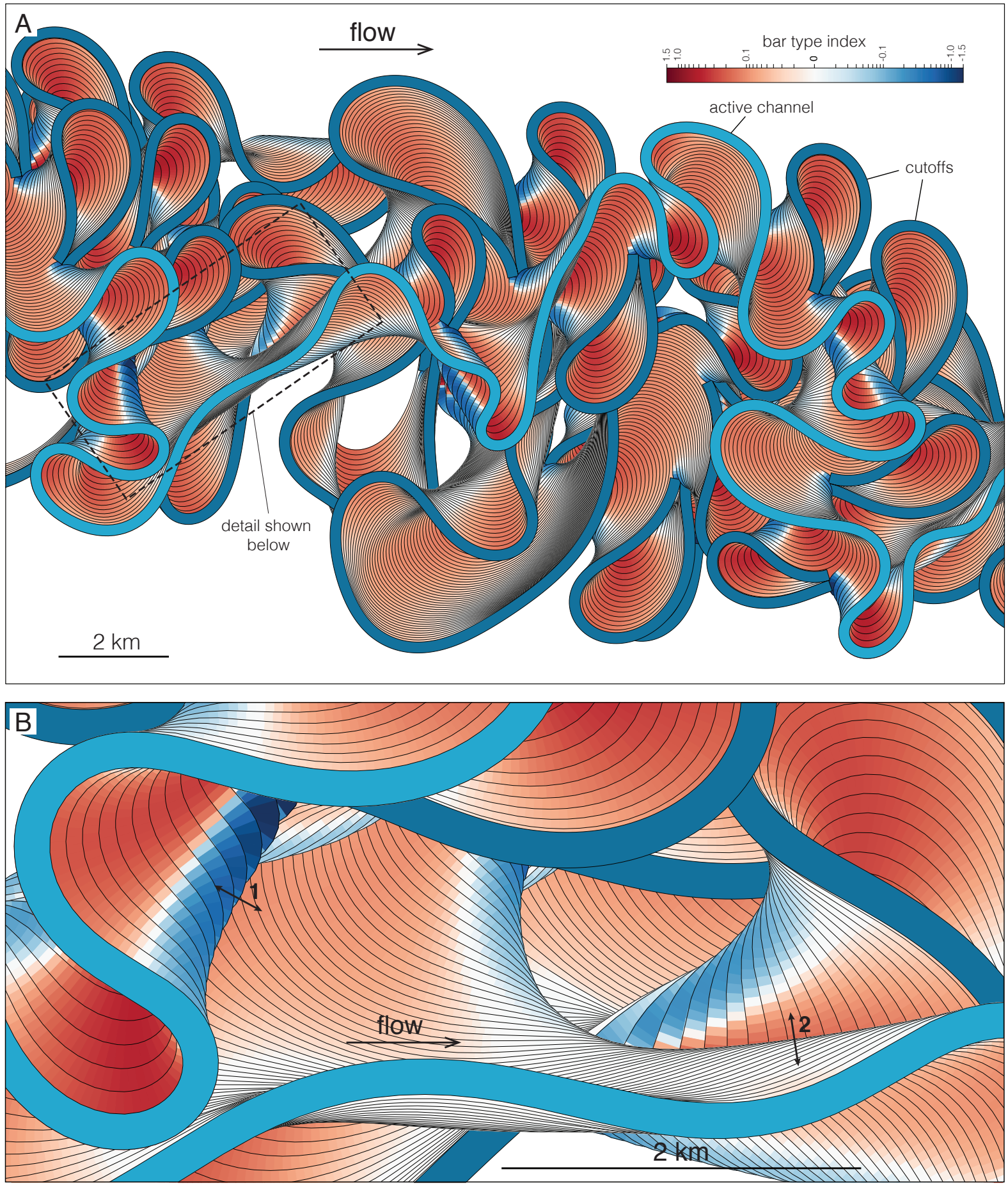

Figure 10. (A) Example of a long-term evolution model colored by the bar type index. Concave bank deposition is associated with erosional surfaces that track downstream translating bends and can have a significant impact on pore-space connectivity between neighboring bar deposits. (B) Detail of area outlined with dashed line in $(\mathrm{A})$. 


\section{Discussion}

The kinematic model reproduces remarkably well many of the observations that we have made on the time-lapse satellite imagery: the pronounced downstream translation of small meander bends and the related concave-bank deposition; the impact of large curvatures not just at the cutoff location, but further downstream as well, resulting in more than one translation zone; and the role of cutoffs and local channel reorganizations in creating the small, predominantly translational bends. However, the satellite imagery suggests that not all translation inside the channel belt is due to 'kinematic' perturbations like cutoffs / channel avulsions. Zones of significant translation and concave bank deposition are also present in places that are not obviously related to recent cutoffs or channel reoccupations. These zones are likely the result of intra-channel-belt variations in erodibility.

While the observed post-cutoff high migration- and translation rate is in part explained by the high curvatures (Sylvester et al., 2019), it has been shown that increased sediment supply associated with cutoff events also plays a role in the increased migration rate (Schwenk and Foufoula-Georgiou, 2016). Measured migration rates along several rivers in the Amazon Basin support this conclusion: cutoff-related bends often show significantly higher migration rates than what is expected from a curvature-based prediction alone (Sylvester et al., 2019).

Although our analysis of the satellite imagery and of the kinematic model provides insights into the relationships between channel kinematics and counter point bar deposition, it does not address the cause of finer-grained deposition along concave banks. The satellite images suggest that concave bank deposition is often associated with anomalously large river widths (e.g., Figs. 5A, 6A), probably as a result of low deposition rates at these locations: the concave bank cannot keep up with the rapidly eroding inner bank of the river. The presence of numerous lakes along these translational zones (Figs. 5-7) is also evidence for lower rates of deposition and lower elevations; stronger compaction in fine-grained sediment might also contribute to this effect. A flow separation zone often develops in locations with concave bank deposition (e.g., Page and Nanson, 1982; Vietz et al., 2012); and it has been suggested that this separation zone results in energy loss and reduced migration rates (Hickin, 1978; Blanckaert, 2011). However, along the Mamoré River, bends with well-defined counter point bars have some of the highest migration rates. Therefore, the development of the flow separation zone and the associated fine-grained deposition is likely to be the effect, not the cause of unusual local channel kinematics (see also Sylvester et al., 2019); and it is the result of increased channel migration rates. The presence of the flow separation zone helps explain the finer-grained nature of some of the counter-point bar deposits, as flow velocities are significantly reduced and only suspended sediment is carried into the separation zone (e.g., Hickin, 1979). Another implication of these observations is that bar push (van de Lageweg et al., 2014; Mason and Mohrig, 2018) is unlikely to be the cause of erosion along the banks opposite of zones of concave-bank deposition; although studies with higher spatial and temporal resolution would be needed to demonstrate that deposition lags behind erosion.

A simple kinematic model of meandering allows us to explore the post-cutoff evolution of channel bends over longer time scales; the results suggest that autogenic counter point bars are more common along the current river location as more mature meanders are the ones preferentially preserved in the older channel belt stratigraphy (Fig. 10). However, autogenic counter point bars are still likely to form a significant part of the stratigraphic record of meandering channels and to have a major impact on the distribution of large-scale heterogeneity in these depositional systems.

The autogenic development of counter point bars also has ecological implications. Compared to typical point bars, river segments with counter point bars are characterized by lower elevations, larger river widths, the common presence of stagnant water bodies, and relatively high bank migration rates. These characteristics have a strong impact on the rate of establishment of vegetation, and the distribution of biomass and species (e.g., Nanson and Beach, 1977; Perucca et al., 2006).

\section{Conclusions}

To summarize our results, time-lapse satellite imagery covering more than thirty years of change along a 375 $\mathrm{km}$ long stretch of the Mamoré River in Bolivia and a simple kinematic model of meandering suggest that translation and the associated concave bank deposition are intrinsic features of river meandering. Previous work has demonstrated that erosion-resistant barriers that force downstream translation of meander bends 
are common causes of concave bank deposition and counter point bar formation (Smith et al., 2009); we have shown here that this phenomenon is also common in the absence of significant changes in erodibility.

The main cause of this type of downstream translation is the phase lag between curvature and migration rate. In small enough bends the point of maximum migration falls close to the downstream inflection point of the bend and this results in downstream translation (Fig. 8). Over a segment of such bends, there is deposition on the concave bank and erosion on the convex bank. The length of this segment is set by the lag between curvature and migration rate; therefore, concave bank deposits and counter point bars that originate this way tend to have a characteristic length. On the other hand, large, mature bends are dominated by expansion as the phase lag is small relative to the arc length of the meander. Such bends often also have segments with concave bank deposition; however, the migration rates are typically among the lowest in the system.

A dimensionless parameter called the 'bar type index' can be used to characterize and predict the location of concave bank deposition and counter point bars. The bar type index is the product of dimensionless curvature and normalized migration rate; it is negative where concave bank deposition occurs. The higher the migration rate and curvature, the higher the absolute value of the bar type index. Curvature and migration rate are related; and short bends with high curvatures and high migration rates are the ones with strongly negative bar type indices. These bends are perturbations of the channel that form at locations of channel reorganization like cutoffs and channel reoccupations. Further work is needed to verify whether the bar type index correlates with sand content or grain size of the corresponding deposits; but our observations suggest that there is a good correlation between negative values of the bar type index and areas with low elevations and lakes in satellite images.

\section{Acknowledgements}

We are grateful for discussions with Jake Covault and to sponsors of the Quantitative Clastics Laboratory consortium at the Bureau of Economic Geology, The University of Texas at Austin (http://www.beg.utexas.edu/qcl). We also thank Planet Labs, Inc. for providing access to their high-resolution satellite imagery.

\section{$7 \quad$ References}

Aalto, R., Maurice-Bourgoin, L., Dunne, T., Montgomery, D.R., Nittrouer, C.A., and Guyot, J.L., 2003, Episodic sediment accumulation on Amazonian flood plains influenced by El Nino/Southern Oscillation: Nature, v. 425, p. 493-497.

Blanckaert, K., 2011, Hydrodynamic processes in sharp meander bends and their morphological implications: Processes in sharp meander bends: Journal of Geophysical Research: Earth Surface, v. 116, F01003, doi:10.1029/2010JF001806.

Colombera, L., Mountney, N.P., Russell, C.E., Shiers, M.N., and McCaffrey, W.D., 2017, Geometry and compartmentalization of fluvial meander-belt reservoirs at the bar-form scale: Quantitative insight from outcrop, modern and subsurface analogues: Marine and Petroleum Geology, v. 82, p. 35-55.

Constantine, J.A., Dunne, T., Ahmed, J., Legleiter, C., and Lazarus, E.D., 2014, Sediment supply as a driver of river meandering and floodplain evolution in the Amazon Basin: Nature Geoscience, v. 7, p. 899-903.

Durkin, P.R., Boyd, R.L., Hubbard, S.M., Shultz, A.W., Blum, M.D., 2017, Three-Dimensional Reconstruction of Meander-Belt Evolution, Cretaceous McMurray Formation, Alberta Foreland Basin, Canada: Journal of Sedimentary Research, v. 87, p. 1075-1099.

Durkin, P.R., Hubbard, S.M., Boyd, R.L., and Leckie, D.A., 2015, Stratigraphic Expression of Intra-Point-Bar Erosion and Rotation: Journal of Sedimentary Research, v. 85, p. 1238-1257.

Durkin, P.R., Hubbard, S.M., Smith, D.G., and Leckie, D.A., 2018, Predicting heterogeneity in meandering fluvial and tidal-fluvial deposits: the point bar to counter point bar transition, in Ghinassi, M. Colombera, L., Mountney, N.P. and Reesink, A.J.H., eds., Fluvial Meanders and Their Sedimentary Products in the Rock Record: International Association of Sedimentologists Special Publication 48, p. 231-250. 
Furbish, D.J., 1991, Spatial autoregressive structure in meander evolution: Geological Society of America 357 Bulletin, v. 103, p. 1576-1589.

Furbish, D.J., 1988, River-bend curvature and migration: How are they related?: Geology, v. 16, p. $752-755$.

Ghinassi, M., D’Alpaos, A., Gasparotto, A., Carniello, L., Brivio, L., Finotello, A., Roner, M., Franceschinis, E., Realdon, N., Howes, N., and Cantelli, A., 2018, Morphodynamic evolution and stratal architecture of translating tidal point bars: Inferences from the northern Venice Lagoon (Italy).

Sedimentology, v. 65, p. 1354-1377.

Ghinassi, M., Ielpi, A., Aldinucci, M., and Fustic, M., 2016, Downstream-migrating fluvial point bars in the rock record: Sedimentary Geology, v. 334, p. 66-96.

Güneralp, I., and Rhoads, B.L., 2009, Empirical analysis of the planform curvature-migration relation of meandering rivers: Water Resources Research, v. 45, W09424.

Guyot, J.L., Jouanneau, J.M., and Wasson, J.G., 1999, Characterisation of river bed and suspended sediments in the Rio Madeira drainage basin (Bolivian Amazonia): Journal of South American Earth Sciences, v. 12, p. 401-410.

Hickin, E., 1978, Mean flow structure in meanders of the Squamish River, British Columbia: Canadian Journal of Earth Sciences, v. 15, p. 1833-1849.

Hickin, E., and Nanson, G., 1975, The Character of channel migration on the Beatton River, Northeast British Columbia, Canada: Geological Society of America Bulletin, v. 86, p. 487-494.

Hickin, E.J., 1979, Concave-bank benches on the Squamish River, British Columbia, Canada: Canadian Journal of Earth Sciences, v. 16, p. 200-203.

Hickin, E.J., 1986, Concave-bank benches in the floodplains of Muskwa and Fort Nelson Rivers, British Columbia: Canadian Geographer, v. 30, p. 111-122.

Howard, A.D., and Knutson, T., 1984, Sufficient Conditions for River Meandering: A Simulation Approach: Water Resources Research, v. 20, p. 1659-1667.

Hubbard, S.M., Smith, D.G., Nielsen, H., Leckie, D.A., Fustic, M., Spencer, R.J., and Bloom, L., 2011, Seismic geomorphology and sedimentology of a tidally influenced river deposit, Lower Cretaceous Athabasca oil sands, Alberta, Canada: AAPG Bulletin, v. 95, p. 1123-1145.

Hudson, P.F., and Kesel, R.H., 2000, Channel migration and meander-bend curvature in the lower Mississippi River prior to major human modification: Geology, v. 28, p. 531-534.

Ielpi, A., and Ghinassi, M., 2014, Planform architecture, stratigraphic signature and morphodynamics of an exhumed Jurassic meander plain (Scalby Formation, Yorkshire, UK): Sedimentology, v. 61, p. 1923-1960.

Ikeda, S., Parker, G., and Sawai, K., 1981, Bend theory of river meanders. Part 1. Linear development: Journal of Fluid Mechanics, v. 112, p. 363-377.

Isikdogan, F., Bovik, A., and Passalacqua, P., 2015, Automatic Channel Network Extraction From

Remotely Sensed Images by Singularity Analysis: IEEE Geoscience and Remote Sensing Letters, v. 12, p. $2218-2221$.

Isikdogan, F., Bovik, A., and Passalacqua, P., 2017, RivaMap: An automated river analysis and mapping engine: Remote Sensing of the Environment, v. 202, p. 1-10.

Lisiecki, L.E., Lisiecki, P.A., 2002, Application of dynamic programming to the correlation of paleoclimate records. Paleoceanography, v. 17, 1049, doi:10.1029/2001PA000733.

Makaske, B., and Weerts, H., 2005, Muddy lateral accretion and low stream power in a sub-recent confined channel belt, Rhine-Meuse delta, central Netherlands: Sedimentology, v. 52, p. 651-668.

Mason, J., and Mohrig, D., 2018, Using Time-Lapse Lidar to Quantify River Bend Evolution on the Meandering Coastal Trinity River, Texas, USA: Journal of Geophysical Research: Earth Surface, v. 123, p. $1133-1144$.

Nanson, G.C., and Beach, H.F., 1977, Forest Succession and Sedimentation on a Meandering-River Floodplain, Northeast British Columbia, Canada: Journal of Biogeography, v. 4, p. 229-251.

Page, K., and Nanson, G., 1982, Concave-bank benches and associated floodplain formation: Earth Surface Processes and Landforms, v. 7, p. 529-543.

Page, K., Nanson, G., 1982, Concave-bank benches and associated floodplain formation: Earth Surface Processes and Landforms, v. 7, p. 529-543.

Perucca, E., Camporeale, C., and Ridolfi, L., 2006, Influence of river meandering dynamics on riparian vegetation pattern formation: Journal of Geophysical Research, v. 111, G01001, doi:10.1029/2005JG000073. 
Savitzky, A., and Golay, M.J.E., 1964, Smoothing and Differentiation of Data by Simplified Least Squares 411 Procedures: Analytical Chemistry, v. 36, p. 1627-1639.

Schwenk, J., Foufoula-Georgiou, E., 2016, Meander cutoffs nonlocally accelerate upstream and

downstream migration and channel widening: Geophysical Research Letters, v. 43, p. 12,437-12,445.

Seminara, G., 2006, Meanders: Journal of Fluid Mechanics, v. 554, p. 271-297.

Smith, D.G., Hubbard, S.M., Leckie, D.A., and Fustic, M., 2009, Counter point bar deposits: lithofacies and reservoir significance in the meandering modern Peace River and ancient McMurray Formation, Alberta, Canada: Sedimentology, v. 56, p. 1655-1669.

Sun, T., Meakin, P., Jøssang, T., and Schwarz, K., 1996, A simulation model for meandering rivers: Water Resources Research, v. 32, p. 2937-2954.

Sylvester, Z., Durkin, P.R., and Covault, J.A., 2019, High curvatures drive river meandering: Geology, v. 421 47, p. 263-266.

Thames, A.C., Bourges, J., Abasto, L.N., Albornoz, E., and Carrasco, L.M., 1993, Rio Mamore: Hidromorfologia y caudales puerto varador. Orstom - Servicio de hidrografia naval, Bolivia. (1993).

van de Lageweg, W.I., van Dijk, W.M., Baar, A.W., Rutten, J., and Kleinhans, M.G., 2014, Bank pull or ${ }^{425}$ bar push: What drives scroll-bar formation in meandering rivers?: Geology, v. 42, p. 319-322.

Vietz, G.J., Rutherfurd, I.D., Stewardson, M.J., and Finlayson, B.L., 2012, Hydrodynamics and sedimentology of concave benches in a lowland river: Geomorphology, v. 147-148, p. 86-101.

Willis, B.J., and Tang, H., 2010, Three-Dimensional Connectivity of Point-Bar Deposits: Journal of Sedimentary Research, v. 80, p. 440-454.

$\mathrm{Xu}, \mathrm{H} ., 2006$, Modification of normalised difference water index (NDWI) to enhance open water features in remotely sensed imagery: International Journal of Remote Sensing, v. 27, p. 3025-3033.

Zinger, J.A, Rhoads, B.L., Best, J.L., 2011, Extreme sediment pulses generated by bend cutoffs along a large meandering river: Nature Geoscience, v. 4, p. 675-678. 